\title{
Predictors of Psychological Well-Being during Behavioral Obesity Treatment in Women
}

\author{
Paulo N. Vieira, Jutta Mata, Marlene N. Silva, Sílvia R. Coutinho, Teresa C. Santos, \\ Cláudia S. Minderico, Luís B. Sardinha, and Pedro J. Teixeira \\ Faculty of Human Kinetics, Technical University of Lisbon, Estrada da Costa, 1495-688 Cruz-Quebrada, Portugal \\ Correspondence should be addressed to Pedro J. Teixeira, pteixeira@fmh.utl.pt
}

Received 22 June 2010; Revised 12 September 2010; Accepted 28 September 2010

Academic Editor: Neil King

Copyright (C) 2011 Paulo N. Vieira et al. This is an open access article distributed under the Creative Commons Attribution License, which permits unrestricted use, distribution, and reproduction in any medium, provided the original work is properly cited.

\begin{abstract}
This study examined the association of autonomy-related variables, including exercise motivation, with psychological wellbeing and quality of life, during obesity treatment. Middle-aged overweight/obese women $(n=239)$ participated in a 1 year behavioral program and completed questionnaires measuring need support, general self-determination, and exercise and treatment motivation. General and obesity-specific health-related quality of life (HRQOL), self-esteem, depression, and anxiety were also assessed. Results showed positive correlations of self-determination and perceived need support with HRQOL and selfesteem, and negative associations with depression and anxiety $(P<.001)$. Treatment autonomous motivation correlated positively with physical $(P=.004)$ and weight-related HRQOL $(P<.001)$, and negatively with depression $(P=.025)$ and anxiety $(P=.001)$. Exercise autonomous motivation was positively correlated with physical HRQOL $(P<.001)$, mental HRQOL $(P=.003)$, weightrelated HRQOL $(P<.001)$, and self-esteem $(P=.003)$, and negatively with anxiety $(P=.016)$. Findings confirm that selfdetermination theory's predictions apply to this population and setting, showing that self-determination, perceived need support, and autonomous self-regulation positively predict HRQOL and psychological well-being.
\end{abstract}

\section{Introduction}

Self-determination theory is a well-known psychological framework to study people's behavior, based on the assumption that humans are innately motivated toward growth and health, a process which can be nurtured or thwarted by the social environment $[1,2]$. Much research on selfdetermination theory, particularly in the health domain, has focused on the study of the characteristics of motivation and associated regulatory processes. For instance, the degree to which people feel autonomous (i.e., self-determined) versus controlled in their motivated pursuits, and how this relates to behavioral persistence (e.g., $[3,4]$ ). Intrinsic motivation, the doing of an activity for its inherent satisfactions, is highly autonomous and represents the prototypic instance of self-determination, while extrinsically motivated behaviors, by contrast, cover the continuum between amotivation and intrinsic motivation, varying in the extent to which their regulation is autonomous. Within extrinsic regulations, autonomous regulations (identified and integrated) reflect a sense of personal volition and recognition of the importance of the target behavior and its consequences. In contrast, in controlled regulations (external and introjected) people feel forced to comply with outside demands or feel guilty or ashamed if they do not perform the target behavior $[1,2]$.

The concept of basic needs is central for selfdetermination theory. It states that people have innate psychological needs that when fulfilled have an effect on personal growth, psychosocial adjustment, feelings of integrity, and well-being [5]. Additionally, it clarifies the relationships between the satisfaction of the needs for competence, autonomy, and relatedness and psychological functioning and well-being. It should be noted that, from a self-determination theory perspective, well-being is not concerned exclusively with "hedonic" or subjective wellbeing in the tradition of Positive Psychology [6], namely, the experience of happiness, usually characterized by high positive affect, reduced negative affect, and life satisfaction 
[7]. Self-determination theory favors a "eudaimonic" view of well-being, focused on feeling fully functioning, selfcoherent, and with a deep sense of wellness, and vitality [8], rooted on the idea of fulfilling or realizing one's daimon or true nature [9]. As a consequence of this broader notion of well-being, which includes happiness and emotional wellbeing but also meaning and personal growth, psychological well-being has been assessed in self-determination theory studies with indicators of positive affect and mental health. Some examples are self-esteem, vitality, life satisfaction, and also (low levels of) depression and anxiety $[10,11]$.

Previous studies in exercise contexts which examined perceived choice, a marker of autonomy, in relation to wellbeing found that it was associated with reduced negative affect [12] and positive well-being [13]. More recent studies in the exercise domain showed that the satisfaction of basic psychological needs for competence, autonomy, and relatedness enhanced psychological well-being in the form of physical self-perception [14], subjective vitality and positive affect $[10,11]$, enjoyment and intrinsic motivation for exercise [15], and satisfaction with life [11].

Numerous studies have demonstrated that obese individuals experience significant impairments in health-related quality of life (HRQOL) as a result of their weight, with greater impairments being associated with greater degrees of obesity [16-18]. Conversely, weight loss has been shown to improve quality of life in obese persons undergoing a variety of treatments [16]. Assessing quality of life is especially important to help determine the comparative efficacy of different treatments and to assess the impact of treatment on how patients feel and function in their everyday life $[19,20]$. The use of both general and specific quality of life instruments is a methodological recommendation from previous obesity HRQOL research [21].

HRQOL, as measured by the SF-36, improves after small to moderate amounts of weight loss with nonsurgical methods [16]. Not only weight loss [22] but also weight maintenance is considered to be beneficial for physical HRQOL [23]. Using obesity-specific measures, such as the IWQOL and IWQOL-Lite, quality of life improvements were associated with decrease in body weight in different studies [22, 24-26]. In a recent meta-analysis, weight loss treatment was associated with lowered depression and increased selfesteem [27]; only treatments that produced actual weight loss predicted increased self-esteem, whereas improvements in depression were independent of weight loss.

In Portugal, the prevalence of overweight and obesity is $53.6 \%$ in adult women; of these $13.4 \%$ are obese and $34.4 \%$ are overweight [28]. However, there are very few studies that have analyzed markers of quality of life and well-being among the Portuguese population, particularly in overweight or obese individuals. One study showed that body image and physical dimensions of obesity-specific quality of life improved significantly during the course of treatment [29]. Another study indicated that changes in weight and body image may reciprocally affect each other during the course of behavioral obesity treatment, and that weight loss partially mediated the effect of treatment on quality of life and on selfesteem [30].
In the present study, our goal was to assess the association of perceived need support, general self-determination (as measured by perceived choice), and treatment and exercise motivation (autonomous versus controlled regulation) with variables reflecting psychological well-being and quality of life, during a behavioral obesity treatment program lasting 1 year. Based on self-determination theory, we predicted that higher perceived need support, higher self-determination, and more autonomous treatment and exercise self-regulation would be associated with higher HRQOL and improved psychological well-being. To our knowledge, only a few studies have examined predictors of psychological well-being in overweight/obese persons during behavioral treatment $[29,30]$ and none have tested self-determination theory variables as putative predictors.

\section{Materials and Methods}

2.1. Design. The study was conducted within a randomized controlled trial in overweight and moderately obese women, primarily focused on increasing exercise self-motivation and exercise adherence, aiming at long-term weight control. The intervention group participated in weekly or bimonthly sessions during approximately one year. The program's principles and intervention style were based on self-determination theory, while the control group received a general health education program. The intervention and its theoretical rationale have been described in detail elsewhere $[31,32]$. The Faculty of Human Kinetics Ethics Committee reviewed and approved the study.

2.2. Participants. Participants $(n=239,37.6 \pm 7.1$ years old; $\mathrm{BMI}=31.5 \pm 4.1 \mathrm{~kg} / \mathrm{m}^{2}$ ) were recruited from the community at large through media advertisements. About $67 \%$ of the study participants had at least some college education, 23\% had between 10 and 12 years of school and $10 \%$ had 9 years or less of school. At baseline, women in the intervention group did not differ from those in the control group in terms of BMI, age, education, or marital status [31]. There were also no differences between the 208 women who completed the 12-month intervention and the 31 who withdrew from the program, for any demographic or baseline psychosocial variable, with the exception of age; women who stayed in the program were on average four years older $(P=.01)$.

2.3. Measurements. Data was collected at baseline, corresponding to the pretreatment scores, and at 12 months, corresponding to the end of the treatment. The instruments were validated Portuguese versions of some of the most commonly used psychosocial instruments in obesity research and are described in detail below.

2.3.1. Self-Determination Measures. Self-determination was assessed with the Perceived Choice subscale from the SelfDetermination Scale [33], an instrument designed to evaluate individual differences in the extent to which people function in a self-determined way (e.g., "I do what I do because it interests me", "I do what I do because I have to", 
"What I do is often not what I'd choose to do"). Cronbach's $\alpha$ was 0.83 . Participants' perceived need support was evaluated with the Health Care Climate Questionnaire [3]. It includes items reflecting fostering of autonomy (e.g., "I feel that the staff has provided me choices and options"), involvement (e.g., "The staff handles peoples' emotions very well"), and the provision of structure (e.g., "the staff has made sure I really understand my condition and what I need to do"). Total score is calculated by summing response items, higher scores indicating higher perceptions of need support climate (Cronbach's $\alpha=0.96$ ).

Self-regulation for treatment was measured with the Treatment Self-Regulation Questionnaire [3] assessing the degree to which a person's motivation for participating in treatment is autonomous versus controlled. Items are summed into two subscales, one measuring autonomous (Cronbach's $\alpha=0.86$ ), the other controlled (Cronbach's $\alpha=0.80$ ) regulation. Exercise regulations were assessed by the Self-Regulation Questionnaire for Exercise [34] measuring exercise regulatory motives. The scale can also be summarized into two subscales, autonomous (Cronbach's $\alpha=0.91$ ) and controlled exercise regulation (Cronbach's $\alpha=0.73)$.

2.3.2. Health-Related Quality of Life Measures. General quality of life was measured with the SF-36 $[35,36]$, composed of two scales and a total of 36 items, reflecting physical (physical component summary, PCS) and psychological (mental component summary, MCS) composite values (Cronbach's $\alpha$ between 0.66 to 0.87 ), in which higher results represent greater quality of life perception. The weight-related aspects of health-related quality of life was assessed using the Impact of Weight on Quality of Life - Lite scale (IWQOL-L) [37, 38], a 31-item questionnaire (Cronbach's $\alpha=0.93$ ). Higher scores indicate higher weight-related quality of life.

2.3.3. Psychological Well-Being Measures. Self-esteem was assessed with the Rosenberg Self-Concept/Self-Esteem Scale $[39,40]$ with higher scores of the RSES representing greater self-esteem (Cronbach's $\alpha=0.88$ ). Depression was evaluated with the Beck Depression Inventory $[41,42]$, where higher scores represent greater levels of depressive symptoms (Cronbach's $\alpha=0.87$ ). State anxiety was assessed with the StateTrait Anxiety Inventory [43], where higher scores represent greater levels of anxiety (Cronbach's $\alpha=0.92$ ).

2.3.4. Body Weight. Body weight was measured twice with a standardized procedure (average was used) at baseline and at the end of the treatment (12 months) using an electronic scale (SECA model 770, Hamburg, Germany). Height was measured with a balance-mounted stadiometer to the nearest $0.1 \mathrm{~cm}$.

2.4. Statistical Procedures. For quality of life and psychological well-being variables, 12-month standardized residuals were used, calculated by regressing the 12-month value onto the baseline value, producing an outcome variable which is entirely orthogonal to (i.e., adjusted for) the baseline value [44]. Unadjusted 12-month scores were used for treatment and exercise motivation, perceived need support, and self-determination. This option was based on the fact that most participants did not engage in regular exercise at the beginning of the intervention, which yielded exercise self-regulation measures less valid (e.g., "I exercise because I"...). Also, treatment self-regulation (i.e., reasons to stay in treatment) and perceived need support from the intervention team could only be evaluated after participants started the intervention. For consistency, the same procedure was adopted for general self-determination.

Statistical analyses were completed using the Statistical Package for the Social Sciences (PASW Statistics 18). Pearson correlations and partial correlations were used to test associations among all variables in the study, and also to examine associations between the independent variables and a global well-being $\mathrm{z}$-score, computed as mean value of all HRQOL and psychological well-being z-scores, before and after adjusting for group. Stepwise linear regressions were used to analyze the independent effect of self-determination theory's factors on HRQOL and psychological well-being. We ran the same analysis controlling separately for a potential intervention effect and for an effect of weight change on outcomes. Tertiles were computed based on the mean $\mathrm{z}$-score value to define success groups. Mean differences in HRQOL and psychological well-being between women in the "low HRQOL and psychological well-being" and "high HRQOL and psychological well-being" tertile-formed groups were tested using independent $t$-tests. Type I error was set at $\alpha=$ 0.05 (two-tailed) for all tests.

\section{Results}

At the end of the 12-month intervention, there was an overall $87 \%$ retention rate. Correlations among independent variables and measures of well-being are presented in Table 1. Self-determination $(P=.001)$, perceived need support $(P<.001)$, treatment autonomous self-regulation $(P<$ $.001)$, and exercise autonomous self-regulation $(P<.001)$ were positively associated with the global well-being $\mathrm{z}$-score, while treatment controlled self-regulation was negatively correlated with well-being $(P=.001)$. Similar results were found after adjusting for group. More specifically, self-determination correlated positively with HRQOL and self-esteem, and negatively with depression and anxiety. Regarding self-determination theory treatment variables, perceived need support was positively correlated with physical, mental, and weight-related HRQOL, and with selfesteem; in turn, correlations were negative with depression and anxiety. Treatment autonomous self-regulation was positively associated with physical and weight-related HRQOL, negatively with depression and anxiety, and not related to mental HRQOL. Conversely, treatment controlled selfregulation correlated positively with anxiety and negatively with self-esteem, physical, and weight-related HRQOL. For exercise variables, results indicated that autonomous selfregulation was positively associated with HRQOL and selfesteem, but negatively correlated with anxiety. Controlled 
TABLE 1: Self-determination theory variables correlation with HRQOL and psychological well-being (at 12 months).

\begin{tabular}{|c|c|c|c|c|c|c|c|c|}
\hline & PCS HRQOL & MCS HRQOL & Obesity specific HRQOL & Self-Esteem & Depression & Anxiety & z-score $\mathrm{W}$ & vell-being \\
\hline & $r$ & $r$ & $r$ & $r$ & $r$ & $r$ & $r$ & $r$ partial \\
\hline Self-determination & $0.27^{* * *}$ & $0.33^{* * *}$ & $0.18^{*}$ & $0.27^{* * *}$ & $-0.16^{*}$ & $-0.33^{* * *}$ & $0.37^{* * *}$ & $0.36^{* * *}$ \\
\hline $\begin{array}{l}\text { Perceived need } \\
\text { support }\end{array}$ & $0.19^{* *}$ & $0.15^{*}$ & $0.29 * * *$ & $0.15^{*}$ & $-0.16^{*}$ & $-0.25^{* *}$ & $0.28^{* * *}$ & $0.20^{* *}$ \\
\hline $\begin{array}{l}\text { Treatment controlled } \\
\text { self-regulation }\end{array}$ & $-0.14^{*}$ & -0.09 & $-0.26^{* * *}$ & $-0.14^{*}$ & 0.11 & $0.28^{* * *}$ & $-0.23^{* *}$ & $-0.27^{* * *}$ \\
\hline $\begin{array}{l}\text { Treatment } \\
\text { autonomous } \\
\text { self-regulation }\end{array}$ & $0.20^{* *}$ & 0.12 & $0.26^{* * *}$ & 0.12 & $-0.17^{*}$ & $-0.24^{* *}$ & $0.27^{* * *}$ & $0.16^{*}$ \\
\hline $\begin{array}{l}\text { Exercise controlled } \\
\text { self-regulation }\end{array}$ & 0.01 & -0.01 & -0.07 & -0.12 & 0.08 & 0.09 & -0.06 & -0.11 \\
\hline $\begin{array}{l}\text { Exercise autonomous } \\
\text { self-regulation }\end{array}$ & $0.28^{* * *}$ & $0.21^{* *}$ & $0.27^{* * *}$ & $0.15^{*}$ & -0.11 & $-0.17^{*}$ & $0.30^{* * *}$ & $0.23^{* *}$ \\
\hline
\end{tabular}

$r$ : Person's correlation coefficient; ${ }^{*} P<.05,{ }^{*} P<.05,{ }^{* *} P<.001 ; r$ partial: partial correlation coefficient adjusting for group; PCS: physical component summary; MCS: mental component summary; z-score was computed as mean value of all HRQOL and psychological well-being z-scores.

TABLE 2: Multiple regression for psychological well-being z-score at intervention's end.

\begin{tabular}{|c|c|c|c|c|c|}
\hline & $B$ & SE $B$ & $\beta$ & Adj $R^{2}$ & $P$ \\
\hline \multicolumn{6}{|l|}{ Model 1} \\
\hline Self-determination & 0.04 & 0.010 & $.25^{* * *}$ & & \\
\hline Perceived need support & 0.01 & 0.003 & $.16^{*}$ & & \\
\hline Treatment controlled self-regulation & -0.02 & 0.005 & $-.22^{* *}$ & & \\
\hline Exercise autonomous self-regulation & 0.01 & 0.006 & $.18^{*}$ & 0.24 & $<.001$ \\
\hline \multicolumn{6}{|l|}{ Model 2} \\
\hline Group & 0.11 & 0.048 & $.16^{*}$ & & \\
\hline Self-determination & 0.04 & 0.010 & $.28^{* * *}$ & & \\
\hline Perceived need support & 0.01 & 0.003 & $.17^{*}$ & & \\
\hline Treatment controlled self-regulation & -0.02 & 0.005 & $-.22^{* *}$ & 0.24 & $<.001$ \\
\hline \multicolumn{6}{|l|}{ Model 3} \\
\hline Weight change & -0.14 & 0.043 & $-.22^{* *}$ & & \\
\hline Self-determination & 0.04 & 0.010 & $.28^{* * *}$ & & \\
\hline Perceived need support & 0.01 & 0.003 & $.22^{* *}$ & & \\
\hline Treatment controlled self-regulation & -0.02 & 0.005 & $-.20^{* *}$ & 0.28 & $<.001$ \\
\hline
\end{tabular}

z-score was computed as mean value of all HRQOL and psychological well-being $\mathrm{z}$-scores; group was coded as 1 to the intervention group, -1 to the control group; note that a negative weight change represents weight loss (a positive outcome); ${ }^{*} P<.05 ;{ }^{* *} P<.01 ;{ }^{* * *} P<.001$.

exercise self-regulation was generally not associated with psychological outcomes.

Next, we ran multiple regression models, using selfdetermination, perceived need support, treatment selfregulation, and exercise self-regulation as independent variables and global well-being as the dependent variable. Results are presented in Table 2. Self-determination, perceived need support, controlled treatment self-regulation (negative association), and exercise autonomous self-regulation were independent predictors of global psychological well-being and explained $29 \%$ of the variance. To test whether these relations held when adjusting for group (i.e., controlling for the intervention effect), the same regression model was run, this time with group assignment forced into the model. Results were comparable to the unadjusted model $(28 \%$ variance explained, $P<.001$ ); however, only self-determination, controlled treatment self-regulation (negatively), and perceived need support were found to predict psychological well-being (see Model 2 in Table 2). To test if weight change was a confounding factor in these relations, the same regression model was run with weight change also in the model (see Model 3 in Table 2). Results were comparable to Model 2 (33\% variance explained; $P<.001)$.

A final analysis was conducted, comparing z-scored selfdetermination theory variables at the highest and lowest of tertiles of global well-being (z-scored) (see Figure 1). Participants in the higher psychological well-being group had higher self-determination $(P<.001)$, perceived need 


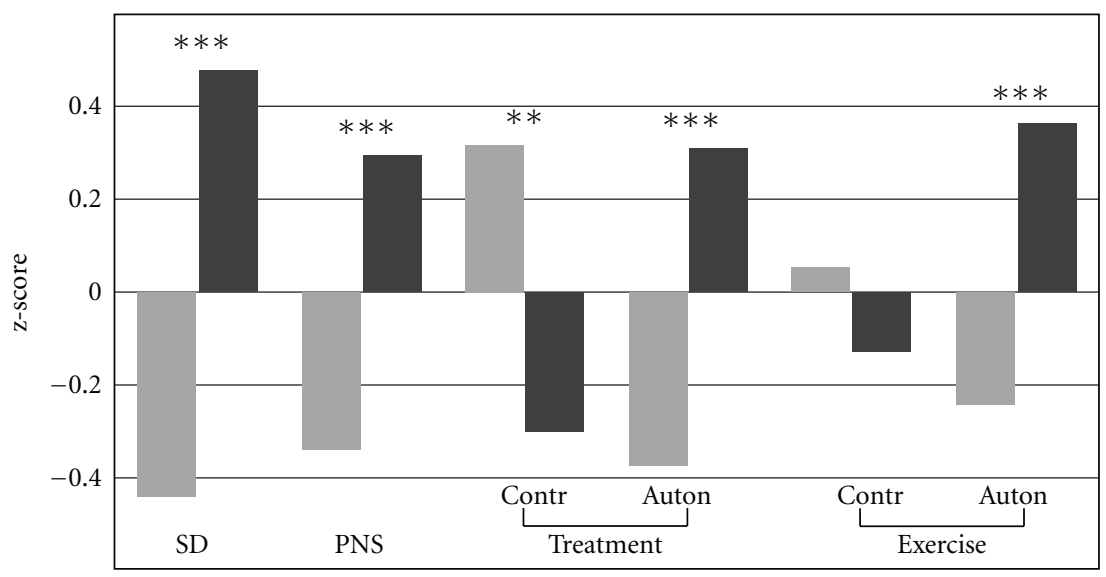

Low HRQOL and PWB

High HRQOL and PWB

FIGURE 1: Self-determination theory-based variables by tertile-split group of HRQOL and psychological well-being (at 12 months). HRQOL: health-related quality of life; PWB: psychological well-being; SD: self-determination; PNS: perceived need support; Contr: controlled; Auton: autonomous; $P$ : $P$ values for independent $t$-test comparing two tertiles considering global HRQOL and PWB z-score, tertile 1 defined as unsuccessful (low) HRQOL and PWB group and tertile 3 defined as successful (high) HRQOL and PWB group; ${ }^{* *} P<.01 ;{ }^{* * *} P<.001$.

support $(P<.001)$, lower treatment controlled self-regulation $(P=.001)$, higher treatment autonomous self-regulation $(P<.001)$, and higher exercise autonomous self-regulation $(P<.001)$. The groups did not differ for exercise controlled self-regulation.

\section{Discussion}

The primary goal of this study was to examine the association of general, contextual (obesity treatment), and situationspecific (exercise-related) measures of self-determination with psychological well-being and HRQOL. To briefly summarize our findings, higher self-determination and perceived need support, lower treatment controlled self-regulation, and higher exercise autonomous self-regulation were significant predictors of well-being in the course of a 1-year behavioral treatment for obesity, before and after adjustment for weight change.

According to self-determination theory, more selfdetermined behavior, which is partially derived from needsupportive interactions with one's environment, leads to improved psychological well-being [45]. This causal path is supported by the present results, the first of this kind to be conducted in the context of behavioral obesity treatment. Additionally, participants in this study who indicated more autonomous reasons to participate in treatment also reported higher scores on most markers of psychological well-being. Finally, women with higher HRQOL and enhanced psychological well-being were those for whom exercise behavior was associated with valued outcomes and/or for whom being physically active was enjoyable and optimally challenging (autonomous regulation). We have previously detailed the mechanisms by which interventions can promote autonomous self-regulation for treatment and specifically for exercise $[31,32]$.
In an exercise-specific context, a study by Wilson et al. showed that if the needs for competence, autonomy, and relatedness in an exercise setting are satisfied, subjective vitality and the degree of positive affect typically experienced within one's exercise session are enhanced [10]. In overweight sedentary women, externally imposed exercise intensity led to a significant decline in ratings of pleasure during exercise session, compared to self-selected intensity [15]. These findings have bearing on the importance of perceived choice in exercising, which could exert positive effects on autonomous regulation, intrinsic motivation, and adherence [15]. Another study with overweight and obese individuals, using positive and negative affect, subjective vitality, and satisfaction with life as measures of well-being, showed that exercise-related autonomy positively predicted satisfaction with life and that intrinsic motivation was a positive predictor of positive affect, while introjected regulation was found to be a negative predictor of subjective vitality [11]. In fact, research generally indicates that more autonomous regulations enhance not only behavioral persistence but also psychological well-being [3, 46, 47]. In contrast, controlled regulations are typically associated with diminished psychological well-being, also reflected in lower self-esteem [48]. Results of the present work are consistent with these findings in showing that treatment and exercise autonomous self-regulation also predict better psychological well-being in overweight or obese women undergoing treatment.

In the present study, as predicted, controlled reasons to stay in treatment predicted poorer psychological wellbeing. However, controlled motivation towards exercise was generally not related to psychological outcomes. As assessed in this study, controlled regulations include reasons with a clear external frame of reference (e.g., "I exercise because I want others to see me as physically fit", "I exercise because 
I want others to see me as physically fit") and reasons which have been introjected or partially internalized (e.g., "I exercise because I'd be afraid of falling too far out of shape", "I exercise because I would feel bad about myself if I did not do it"). One interpretation for the present findings is that external demands and pressures to exercise in this study were perceived by participants as coming mostly from the intervention team. To the extent that this occurred, external contingencies and incentives, which normally could have been felt as controlling and a potential cause of anxiety, may have been perceived as normal, expected, and even positive by some participants. This was likely the case in the main intervention group, for whom introjected, integrated, and intrinsic exercise motivation were found to increase (compared to controls) at the end of an intervention which was overwhelmingly perceived as supporting participants' autonomy [31]. In fact, group differences in the psychological impact of introjected and/or external regulations may partially explain the generally nonsignificant results.

According to self-determination theory, satisfaction of competence, autonomy, and relatedness, the three basic psychological needs, provide a basis for predicting when the pursuit and attainment of goals will be associated with more positive versus more negative well-being outcomes [45]. In contrast, thwarted satisfaction of these needs results in negative functional consequences for mental health. Persistent deprivation of any need has costs for health and well-being, leading to the development of compensatory processes, such as substitute motives and non-autonomous regulatory styles, which are expected to result in worse well-being. Thus, need thwarting conditions lead to specifiable patterns of behaviors, regulations, goals, and affects that do not represent optimal development and well-being, which would occur in supportive environments [45]. Our findings suggest that, in the context of weight loss treatment, perceived need support and autonomous self-regulation will also lead to increased HRQOL and improved psychological well-being.

Several studies showed that weight loss is important in overweight and obese populations in part due to beneficial effects on HRQOL and psychological well-being. For example, Kolotkin and colleagues found that obesityspecific HRQOL changes were strongly related to weight reduction among 161 participants (88\% women) [49]. Additionally, improved mood, affect, and psychological wellbeing may also facilitate the adoption and maintenance of behavior needed to regulate one's weight [30]. Thus, improving psychological well-being is not only ethically appropriate but could also be good clinical practice, to the extent that it contributes to enhanced treatment outcomes. Unfortunately, investigating predictors of psychological wellbeing in obesity treatment has not been the focus of much prior research. An additional ethical medical mandate is to promote patients' autonomy [50]. Interestingly, an increasing body of research shows that promoting autonomy is also advisable from a treatment efficacy viewpoint. For example, in weight loss and weight maintenance, more autonomous and intrinsic motivation have been shown to significantly predict more successful weight and exerciserelated outcomes $[3,51-53]$.
In conclusion, this work supports predictions based on self-determination theory in relation to correlates of quality of live and psychological functioning. For obesity treatment, this study furthers our understanding of mechanisms associated with enhanced psychological outcomes, which is of direct relevance for health care providers in this field. Promoting self-determined motivation for health and health behaviors, particularly exercise, may positively influence a number of relevant psychological variables. Importantly, during weight control, these associations appear to hold independently of actual weight changes.

\section{Acknowledgments}

This study was funded by Grants by the Portuguese Science and Technology Foundation (FCT-POCI/DES/57705/2004 and SFRH/BD/31408/2006 to Paulo Vieira) and the Calouste Gulbenkian Foundation (Grant no. 65565/2004). The investigators are also grateful to the Oeiras City Council, Nestlé Portugal, and IBESA for their additional financial support.

\section{References}

[1] E. Deci and R. Ryan, Intrinsic Motivation and SelfDetermination in Human Behavior, Plenum, New York, NY, USA, 1985.

[2] R. M. Ryan and E. L. Deci, "Self-determination theory and the facilitation of intrinsic motivation, social development, and well-being," American Psychologist, vol. 55, no. 1, pp. 68-78, 2000.

[3] G. C. Williams, V. M. Grow, Z. R. Freedman, R. M. Ryan, and E. L. Deci, "Motivational predictors of weight loss and weightloss maintenance," Journal of Personality and Social Psychology, vol. 70, no. 1, pp. 115-126, 1996.

[4] L. G. Pelletier, M. S. Fortier, R. J. Vallerand, and N. M. Brière, "Associations among perceived autonomy support, forms of self-regulation, and persistence: a prospective study," Motivation and Emotion, vol. 25, no. 4, pp. 279-306, 2001.

[5] E. Deci and R. Ryan, Eds., Handbook of Self-Determination Research, The University of Rochester Press, 2002.

[6] D. Kahneman, E. Diener, and N. Schwartz, Eds., Well-Being: The Foundations of Hedonic Psychology, Russel Sage Found, New York, NY, USA, 1999.

[7] E. Diener and R. E. Lucas, "Personality and subjective wellbeing," in Well-Being: The Foundations of Hedonic Psychology, D. Kahneman, E. Diener, and N. Schwarz, Eds., pp. 213-229, 1999.

[8] R. M. Ryan and E. L. Deci, "On happiness and human potentials: a review of research on hedonic and eudaimonic well-being," Annual Review of Psychology, vol. 52, pp. 141-166, 2001.

[9] A. S. Waterman, “Two conceptions of happiness: contrasts of personal expressiveness (eudaimonia) and hedonic enjoyment," Journal of Personality and Social Psychology, vol. 64, no. 4, pp. 678-691, 1993.

[10] P. M. Wilson, K. Longley, S. Muon, W. M. Rodgers, and T. C. Murray, "Examining the contributions of perceived psychological need satisfaction to well-being in exercise," Journal of Applied Biobehavioral Research, vol. 11, no. 3-4, pp. 243-264, 2006. 
[11] J. Edmunds, N. Ntoumanis, and J. Duda, "Understanding exercise adherence and psychological well-being from a self determination theory perspective among a cohort of obese patients referred to an exercise on prescription scheme," Psychology of Sport \& Exercise, vol. 8, pp. 722-740, 2007.

[12] A. J. Daley and I. W. Maynard, "Preferred exercise mode and affective responses in physically active adults," Psychology of Sport and Exercise, vol. 4, no. 4, pp. 347-356, 2003.

[13] G. Parfitt and C. Gledhill, "The effect of choice of exercise mode on psychological responses," Psychology of Sport and Exercise, vol. 5, no. 2, pp. 111-117, 2004.

[14] M. Hagger and N. Chatzisarantis, Intrinsic Motivation and Self-Determination in Exercise and Sport, Human Kinetics, 2007.

[15] P. Ekkekakis and E. Lind, "Exercise does not feel the same when you are overweight: the impact of self-selected and imposed intensity on affect and exertion," International Journal of Obesity, vol. 30, no. 4, pp. 652-660, 2006.

[16] R. L. Kolotkin, K. Meter, and G. R. Williams, "Quality of life and obesity," Obesity Reviews, vol. 2, no. 4, pp. 219-229, 2001.

[17] R. F. Kushner and G. D. Foster, "Obesity and quality of life," Nutrition, vol. 16, no. 10, pp. 947-952, 2000.

[18] K. R. Fontaine and I. Barofsky, "Obesity and health-related quality of life," Obesity Reviews, vol. 2, no. 3, pp. 173-182, 2001.

[19] K. R. Fontaine and S. J. Bartlett, "Estimating health-related quality of life in obese individuals," Disease Management and Health Outcomes, vol. 3, no. 2, pp. 61-70, 1998.

[20] K. Duval, P. Marceau, L. Pérusse, and Y. Lacasse, "An overview of obesity-specific quality of life questionnaires," Obesity Reviews, vol. 7, no. 4, pp. 347-360, 2006.

[21] R. L. Kolotkin, J. M. Norquist, R. D. Crosby et al., "Oneyear health-related quality of life outcomes in weight loss trial participants: comparison of three measures," Health and Quality of Life Outcomes, vol. 7, Article ID 53, 2009.

[22] G. P. Samsa, R. L. Kolotkin, G. R. Williams, M. H. Nguyen, and C. M. Mendel, "Effect of moderate weight loss on healthrelated quality of life: an analysis of combined data from 4 randomized trials of sibutramine vs placebo," American Journal of Managed Care, vol. 7, no. 9, pp. 875-883, 2001.

[23] J. T. Fine, G. A. Colditz, E. H. Coakley et al., "A prospective study of weight change and health-related quality of life in women," Journal of the American Medical Association, vol. 282, no. 22, pp. 2136-2142, 1999.

[24] R. L. Kolotkin, S. Head, M. Hamilton, and C. K. Tse, "Assessing impact of weight on quality of life," Obesity Research, vol. 3, no. 1, pp. 49-56, 1995.

[25] F. G. McMahon, K. Fujioka, B. N. Singh et al., "Efficacy and safety of sibutramine in obese white and African American patients with hypertension: a 1-year, double-blind, placebocontrolled, multicenter trial," Archives of Internal Medicine, vol. 160, no. 14, pp. 2185-2191, 2000.

[26] S. G. Engel, R. D. Crosby, R. L. Kolotkin et al., "Impact of weight loss and regain on quality of life: mirror image or differential effect?" Obesity Research, vol. 11, no. 10, pp. 1207$1213,2003$.

[27] B. E. Blaine, J. Rodman, and J. M. Newman, "Weight loss treatment and psychological well-being: a review and metaanalysis," Journal of Health Psychology, vol. 12, no. 1, pp. 6682, 2007.

[28] I. do Carmo, O. Dos Santos, J. Camolas et al., "Overweight and obesity in Portugal: national prevalence in 2003-2005," Obesity Reviews, vol. 9, no. 1, pp. 11-19, 2008.
[29] A. L. Palmeira, P. J. Teixeira, T. L. Branco et al., "Predicting short-term weight loss using four leading health behavior change theories," International Journal of Behavioral Nutrition and Physical Activity, vol. 4, Article ID 14, 2007.

[30] A. L. Palmeira, D. A. Markland, M. N. Silva et al., "Reciprocal effects among changes in weight, body image, and other psychological factors during behavioral obesity treatment: a mediation analysis," International Journal of Behavioral Nutrition and Physical Activity, vol. 6, Article ID 9, 2009.

[31] M. N. Silva, P. N. Vieira, S. R. Coutinho et al., "Using selfdetermination theory to promote physical activity and weight control: a randomized controlled trial in women," Journal of Behavioral Medicine, vol. 33, no. 2, pp. 110-122, 2010.

[32] M. N. Silva, D. Markland, C. S. Minderico et al., "A randomized controlled trial to evaluate self-determination theory for exercise adherence and weight control: rationale and intervention description," BMC Public Health, vol. 8, Article ID 234, 2008.

[33] K. M. Sheldon, R. Ryan, and H. T. Reis, "What makes for a good day? Competence and autonomy in the day and in the person," Personality and Social Psychology Bulletin, vol. 22, no. 12, pp. 1270-1279, 1996.

[34] R. M. Ryan and J. P. Connell, "Perceived locus of causality and internalization: examining reasons for acting in two domains," Journal of Personality and Social Psychology, vol. 57, no. 5, pp. 749-761, 1989.

[35] J. Ware et al., SF-36 Health Survey Manual and Interpretation Guide, New England Medical Center, The Health Institute, Boston, Mass, USA, 1993.

[36] P. Lopes Ferreira, "The development of the Portuguese version of the MOS SF-36. Part II-validation testing," Acta Medica Portuguesa, vol. 13, no. 3, pp. 119-127, 2000 (Portuguese).

[37] R. L. Kolotkin and R. D. Crosby, "Psychometric evaluation of the impact of weight on quality of life-lite questionnaire (IWQOL-Lite) in a community sample," Quality of Life Research, vol. 11, no. 2, pp. 157-171, 2002.

[38] S. G. Engel, R. L. Kolotkin, P. J. Teixeira et al., "Psychometric and cross-national evaluation of a Portuguese version of the Impact of Weight on Quality of Life-Lite (IWQOL-Lite) questionnaire," European Eating Disorders Review, vol. 13, no. 2, pp. 133-143, 2005.

[39] M. Rosenberg, Society and the Adolescent Self-Image, Princeton University Press, Princeton, NJ, USA, 1965.

[40] A. Azevedo and L. Faria, "Self-esteem in the scholl' secondary level:validation of the Rosenberg Self-Esteem Scale, Avaliação Psicológica," Formas e Contextos, pp. 415-421, Universidade do Minho, Braga, Portugal, 2004.

[41] A. Beck and R. Steer, Manual for the Beck Depression Inventory, Psychological Corporation, New York, NY, USA, 1987.

[42] J. A. Cunha, Manual for the Portuguese Version of Beck' Scales, The Psychological Corporation, São Paulo, Brazil, 2001.

[43] C. D. Spielberger and P. R. Vagg, "Psychometric properties of the STAI: a reply to Ramanaiah, Franzen, and Schill," Journal of Personality Assessment, vol. 48, no. 1, pp. 95-97, 1984.

[44] J. Cohen and P. Cohen, Applied Multiple Regression/Correlation Analysis for the Behavioral Sciences, Lawrence Erlbaum Associates, Mahwah, NJ, USA, 3nd edition, 2003.

[45] E. L. Deci and R. M. Ryan, "The "what" and "why" of goal pursuits: human needs and the self-determination of behavior," Psychological Inquiry, vol. 11, no. 4, pp. 227-268, 2000 . 
[46] R. M. Ryan, R. W. Plant, and S. O’Malley, "Initial motivations for alcohol treatment: relations with patient characteristics, treatment involvement, and dropout," Addictive Behaviors, vol. 20, no. 3, pp. 279-297, 1995.

[47] E. L. Deci and R. M. Ryan, "Facilitating optimal motivation and psychological well-being across life's domains," Canadian Psychology, vol. 49, no. 1, pp. 14-23, 2008.

[48] M. H. Kernis, A. W. Paradise, D. J. Whitaker, S. R. Wheatman, and B. N. Goldman, "Master of one's psychological domain? Not likely if one's self-esteem is unstable," Personality and Social Psychology Bulletin, vol. 26, no. 10, pp. 1297-1305, 2000.

[49] R. L. Kolotkin, R. D. Crosby, G. R. Williams, G. G. Hartley, and S. Nicol, "The relationship between health-related quality of life and weight loss," Obesity Research, vol. 9, no. 9, pp. 564$571,2001$.

[50] T. L. Beauchamp and J. F. Childress, Principles of Biomedical Ethics, Oxford University Press, Oxford, UK, 3rd edition, 1989.

[51] M. N. Silva et al., "Mediators of different types of physical activity during behavioral obesity treatment," Psychology of Sport and Exercise, vol. 11, pp. 591-601, 2010.

[52] P. J. Teixeira, S. B. Going, L. B. Houtkooper et al., "Exercise motivation, eating, and body image variables as perdictors of weight control," Medicine and Science in Sports and Exercise, vol. 38, no. 1, pp. 179-188, 2006.

[53] P. J. Teixeira, M. N. Silva, S. R. Coutinho et al., "Mediators of weight loss and weight loss maintenance in middle-aged women," Obesity, vol. 18, no. 4, pp. 725-735, 2010. 


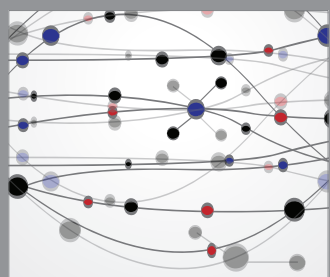

The Scientific World Journal
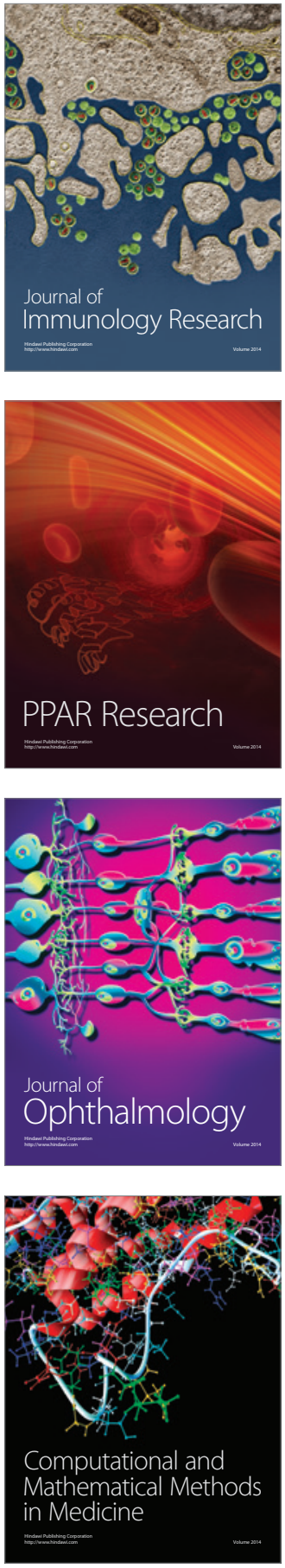

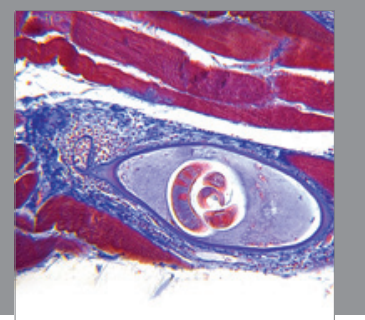

Gastroenterology

Research and Practice
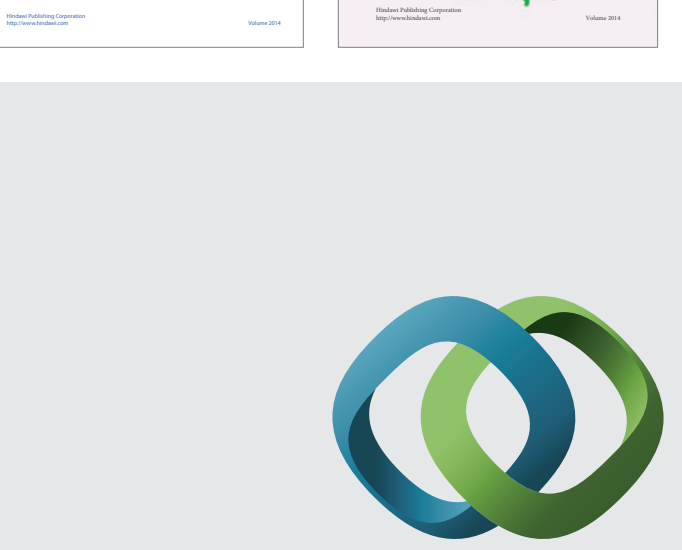

\section{Hindawi}

Submit your manuscripts at

http://www.hindawi.com
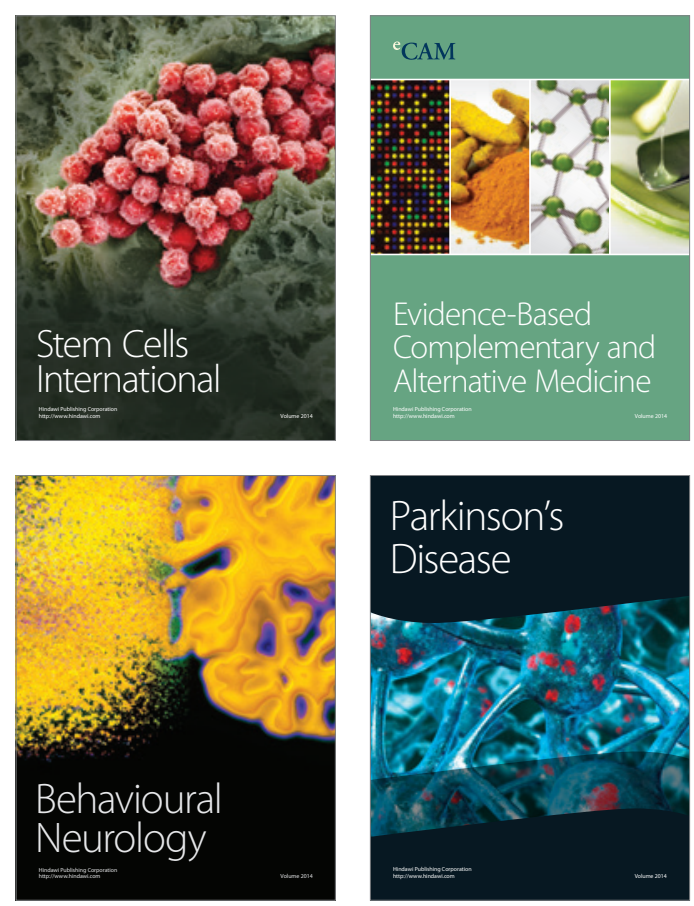

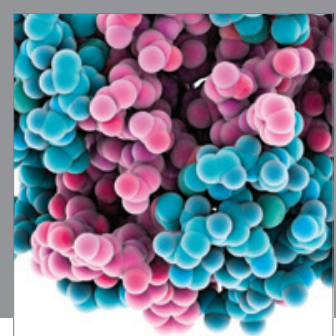

Journal of
Diabetes Research

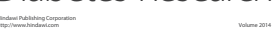

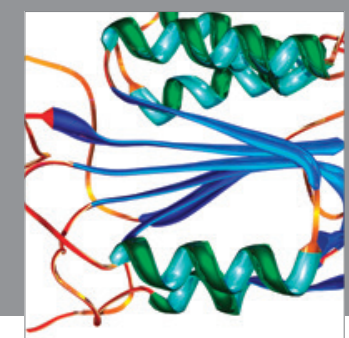

Disease Markers
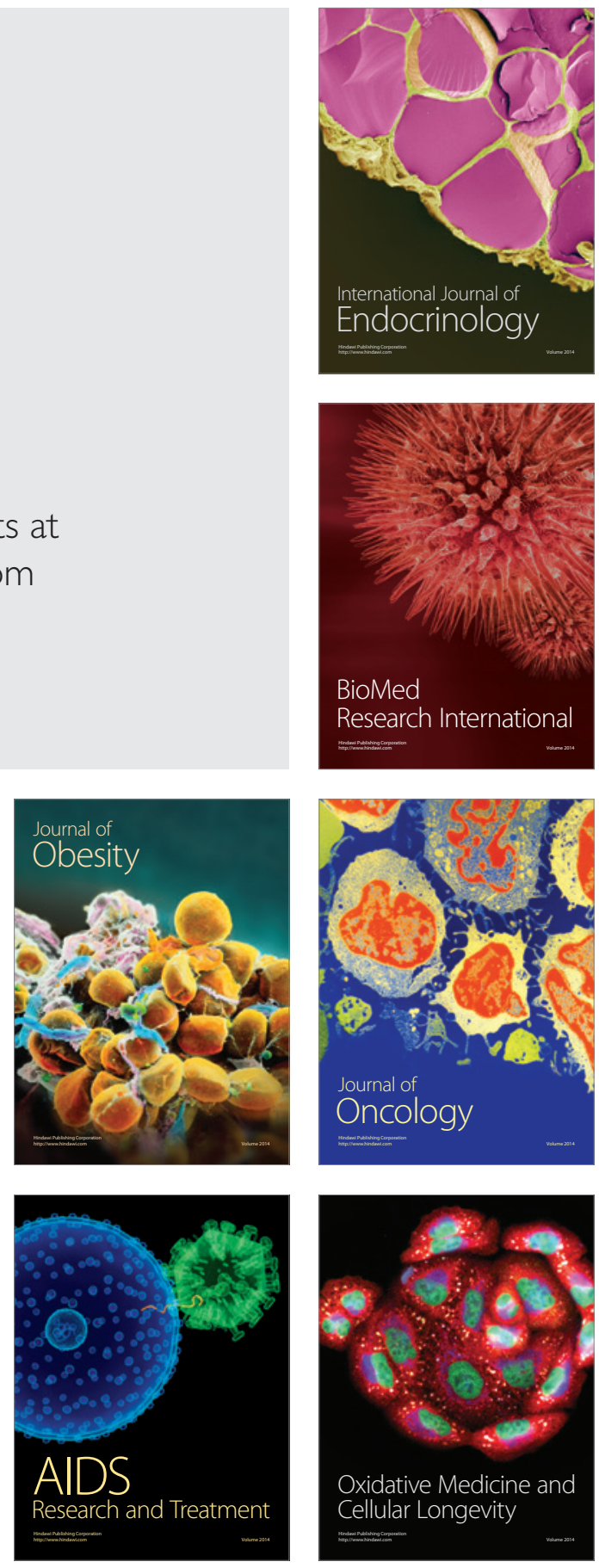